\title{
GDP and Human Development
}

\author{
Gordon Bechtel ${ }^{1}$, Timothy Bechtel ${ }^{2}$ \\ ${ }^{1}$ Warrington College of Business, University of Florida, Gainesville, FL, USA \\ ${ }^{2}$ Aviation Power GmbH, Frankfurt, Germany \\ Email: bechtel@ufl.edu
}

How to cite this paper: Bechtel, G., \& Bechtel, T. (2020). GDP and Human Development. Open Journal of Social Sciences, 8 , 333-343.

https://doi.org/10.4236/jss.2020.811030

Received: October 24, 2020

Accepted: November 27, 2020

Published: November 30, 2020

Copyright $\odot 2020$ by author(s) and Scientific Research Publishing Inc. This work is licensed under the Creative Commons Attribution International License (CC BY 4.0).

http://creativecommons.org/licenses/by/4.0/

\begin{abstract}
Bechtel $(2018,2019)$ linked gross domestic product (GDP) to the United Nation's Human Development Index (HDI). Bechtel, G. and Bechtel, T., 2020 then found that American GDP alone predicted HDI. These results induce the hypotheses that two transforms of GDP perfectly predict a new index of HDI-attenuated GDP (W) introduced here. These hypotheses are confirmed at the global level and for the United States and China, the world's two largest economies. These discoveries inform the debate on well-being and show that $\mathrm{W}$ can be computed from GDP without survey sampling, questionnaire interrogation, probabilistic inference, or significance testing. In view of trade-war and COVID-19 shocks to the global and national economies, international attention to GDP and human development is now compelling.
\end{abstract}

\section{Keywords}

Bottom-Up Capitalism, GDP Contraction, GDP per Capata, Global Data

Science, Goodness of Fit, Internal Consistency, Linear and Iso-Elastic Models, Post-Pandemic Era, Real (vs Random) Variables

\section{Ghandian Economics and Human Development}

Mahatma Ghandi rejected the concept that underlies classical economic thinking; namely that "the human being is a rational actor always seeking to maximize material self-interest [....] His model, by contrast, is aimed at the fulfillment of needs-including the need for meaning and community [....] Ghandi's concept of egalitarianism was centered on the preservation of human dignity rather than material development" (cf. Internet Explorer: Mahatma Ghandi-Wikipedia).

Ghandi advocated local, ground-up creation and ownership of companies rather than control of the supply side by international conglomerates. His major, and revolutionary, economic activity centered on the manufacture of apparel in localities throughout India and South Africa, supplying their poor and hungry 
populations. Ghandi's profitable enterprises in these huge BRICS nations epitomized his egalitarian philosophy of status-quo reform by beginning with whatever the real economy presents. His successful deployment of bottom-up capitalism outmatched the top-down efforts of the British Empire in its failing attempt to control India and the rest of the planet.

The Global Establishment. Mahatma Ghandi's bottom-up capitalism is now updated by the United Nation's Secretary General Antonio Guterres, who advocates corrections to the World Bank, the International Monetary Fund, and the UN Security Council (Aljazeera, accessed on 19 July, 2020). Guterres stresses that events have overtaken us

(https://www.nelsonmandela.org/content/page/annual-lecture-2020):

- The coronavirus has brought the world to the breaking point and exposed deep demographic inequalities.

- A new UN governance would give each nation an equal vote and no veto.

- A new social contract would create equal opportunity at all institutional levels.

- An inclusive and balanced multilateral trading system would provide sustenance and sustainability.

Guterres reiterated these issues at the United Nations $75^{\text {th }}$ anniversary on September 21, 2020. Pursuing "the future we want, the United Nations we need", the UN passed a Declaration of International Collaboration. This document advocates an egalitarian reformation of the UN as well as the entire global establishment.

The present paper. The preceding history shows that any economic analysis of well-being must begin with GDP. Therefore, we initiate our workup in Section 2 with a description of GDP's three classic indicators supplied by the World Bank. These indicators sum to GDP, which is our independent variable. Section 3 describes the United Nation's Human Development Index (HDI), invented by Amartya Sen, and regarded as the world's leading indicator of well-being (http://hdr.undp.org/en/data). Section 4 demonstrates that both linear and iso-elastic transformations of GDP perfectly predict a new Index of HDI-attenuated GDP W, which is our dependent variable. Section 5 discusses these results vis-á-vis global data science and the 2020 pandemic. Section 6 inserts Ghandi's bottom-up capitalism into the current debate on the sustainability of GDP growth.

\section{The GDP Index (G)}

History. In the great depression Simon Kuznetz formulated American national accounts in terms of dollars, which evaluated different commodities in a common unit. He added up various national income sources and reported his result to the United States Senate in January, 1934 (Masood, 2016, Prologue, Chapters 2 and 3). "In 1940, six years after Simon Kuznetz had presented his national income estimates to the Senate, Keynes had written down in a table the basis for what today is the formula for GDP" (Masood, 2016: p. 26). This formula adds up three macro indicators, household expenditure, domestic savings, and 
government expenditure, which constitute Keynesian GDP.

Importance of G. In 1999, mindful of Simon Kuznets original accounting of distinct goods like cars and cereal boxes by their dollar values (Masood, 2016, Introduction), the United States Commerce Department proclaimed the GDP formula as the U.S. government's greatest invention of the $20^{\text {th }}$ century. The calibration of GDP's three indicators in current US dollars for all nations signals a continuing American control of the global economy.

In the plethora of global indexes, GDP looms as the composite most fundamental to the global economy. GDP is so basic, longstanding, and prestigious that market traders, analysts, and policy planners track it daily on worldwide television and internet. The new empirical economics is dominated by GDP's "Making the Modern World" (Masood, 2016, Preface), it's fostering human development, and it's availability in most national accounts (Bechtel, 2019).

Here we view GDP's components, household expenditure, domestic savings, and government expenditure, as separate time-varying indicators (http://beta.data.worldbank.org):

Household final consumption expenditure (current US\$): "Household final consumption expenditure (formerly private consumption) is the market value of all goods and services, including durable products (such as cars, washing machines, and home computers), purchased by households. It excludes purchases of dwellings but includes imputed rent for owner-occupied dwellings. It also includes payments and fees to governments to obtain permits and licenses. Here, household consumption expenditure includes the expenditures of nonprofit institutions serving households, even when reported separately by the country. Data are in current U.S. dollars."

Gross domestic savings (current US\$): “Gross domestic savings are calculated as GDP less final consumption expenditure (total consumption). Data are in current U.S. dollars."

The World Bank's update of Keynes final indicator, added during World War II (Keynes, 1940), is:

General government final consumption expenditure (current US\$): “General government final consumption expenditure (formerly general government consumption) includes all current government expenditures for purchases of goods and services (including compensation of employees). It also includes most expenditures on national defense and security, but excludes government military expenditures that are part of government capital formation. Data are in current U.S. dollars." This dollar denomination of variables counted in different units (automobiles, cereal boxes, etc.) allows the ratio scaling of GDP up to a multiplier calibrating GDP in single, thousands, millions, billions, or trillions of current US dollars. This ratio scaling also allows daily exchange-rates to multiply one nation's currency into another's (e.g. dollars into yen).

Internal Consistency of $\mathrm{G}$. Table 1 displays the correlation matrix for the three components of GDP, each measured by the World Bank at the global level: 
Table 1. Internal consistency of global GDP.

\begin{tabular}{cccc}
\hline & Consum & Gov & Sav \\
\hline Consum & 1.0000 & & \\
Gov & 0.9987 & 1.0000 & \\
Sav & 0.9721 & 0.9657 & 1.0000 \\
\hline
\end{tabular}

If the three off-diagonal correlations in Table 1 were also 1.0000 , then unweighted global GDP

$$
1 * \text { Consum }+1 * \text { Gov }+1 * \text { Sav }
$$

would correlate 1.0000 over time with any weighted linear combination

$$
a * \text { Consum }+b * \operatorname{Gov}+c * \operatorname{Sav}
$$

Table 1 shows that global GDP closely approaches the ideal of a perfect, internally-consistent index (cf. Bechtel, 2019).

\section{The Human Development Index (H)}

"The HDI is a summary measure of average achievement in key dimensions of human development: a long and healthy life, being knowledgeable and having a decent standard of living. The HDI is the geometric mean of normalized indices for each of the three dimensions".

"The health dimension is assessed by life expectancy at birth, the education dimension is measured by mean of years of schooling for adults aged 25 years and more and expected years of schooling for children of school entering age. The standard of living dimension is measured by gross national income per capita". Each of these HDI dimensions is a national result rather than national goal. The UN computes HDI as the geometric mean of these three dimensions of human development.

Explicating the three dimensions and their composite HDI scale, the United Nations Development Program (http://hdr.undp.org/en/data) continues: "The normalized $[0,1]$ scale for health and education (in years) and standard of living (in logarithm-of-dollar-units) is obtained as follows: Minimum and maximum values (goalposts) are set in order to transform the indicators expressed in different units into indices on a scale of 0 to 1 . These goalposts act as the 'natural zeros' and 'aspirational targets', respectively, from which component indicators are standardized. [...] Having defined the minimum and maximum values, the dimension indices are calculated as the ratio of actual value minus minimum value to maximum value minus minimum value. For the education dimension, this ratio is first applied to each of the two indicators, and then the arithmetic mean of the two resulting indices is taken $[\ldots]$ ".

"Because each dimension index is a proxy for capabilities in the corresponding dimension, the transformation function from income to capabilities is likely to be concave-that is, each additional dollar of income has a smaller effect on expanding capabilities. Thus, for income, the natural logarithm of the actual, 
minimum and maximum values is used".

The conversion of HDI's three dimensions to a common $[0,1]$ scale was accomplished by Amartya Sen (Masood, 2016: pp. 93-95). Sen's natural zeros and aspirational targets are calibrated in years for life span and lifetime schooling. For standard of living these goalposts are measured in logarithm-of-dollar-units. The above ratio then places health, education, and standard of living in the closed interval $[0,1]$. The geometric mean of these three points is the HDI, which is also in $[0,1]$.

Internal Consistency of HDI. Close relationships among HDI's three dimensions have been confirmed in several studies:

"Statistical analysis of data from many countries shows a strong correlation between per capita income and decreased mortality" (Taylor \& Hall, 1967). The positive effect of education on life expectancy has been shown by Brita Roy (https://medicine.yale.edu/profile/britta_roy/?tab=research). The effect of parental income on their children's education has been demonstrated by Reardon (2012), and Autor (2014) has shown that children's education strongly predicts their later income.

Finally, internal consistency among HDI's three dimensions has also been reported by van Raalte, Sasson, and Martikainen (2018). They found that life expectancy (average at death) ranks perfectly with Finnish educational level and occupational class for nine successive time points over 1970-2015. These authors also found that Finnish life expectancy ranks perfectly with the Finnish income quintile for four successive time points over 2000-2015.

\section{The Index of HDI-Attenuated GDP (W)}

In this section $\mathrm{W}, \mathrm{H}, \mathrm{G}, \mathrm{P}$, and global GDP per Capata denote column vectors, i.e. spread-sheet variables. The first variable $\mathrm{W}$ measures global HDI-attenuated GDP over 262 countries:

$$
\$ \mathbf{W}=\text { \$global GDP per Capata } * \mathbf{H}
$$

where the values of the two right-side vectors are in 1 to 1 correspondence. * denotes the row-wise multiplication of the 29 values in each of these column vectors. This row-wise multiplication creates our dependent variable $\mathrm{W}$. We calibrate $\mathrm{W}$ in thousands of current US\$. Our independent variable $\mathrm{G}$ has been calibrated in trillions of current US\$ by the World Bank (cf. Section 2).

As described in Section 3, the United Nations defines $\mathrm{H}$ as aggregate human development. Formula (1) parts with this tradition by conceptualizing the values of $\mathrm{H}$ as multipliers between 0 and 1 that attenuate the vector global GDP percapata in defining HDI-attenuated GDP. The values of global GDP percapata have trended upward in dollars from 1990 through 2018. The values of our multipliers have also trended upward, producing rising $\mathrm{W}$ over these same years. We regard the denomination of $\mathrm{W}$ on a monetary scale, rather than on the interval $[0,1]$, as an important innovation in economic measurement. 
W as a Linear Function of G. A nation's dollars in household expenditure, domestic savings, and government expenditure reveal its allocation of resources. For example, the American Federal Reserve is guided by the datum that two thirds of American GDP is household expenditure. Conversely, the bulk of Chinese GDP is domestic savings. The International Monetary Fund (IMF), especially sensitive to China's global influence, has noted that Chinese government policy is now "designed to accelerate the transformation of the Chinese economic model, improve livelihoods, and raise domestic consumption" (Singh, Nabar, \& N'Diaye, 2013). The IMF's sensitivity to China is due to Chinese and American GDP making up 41\% of global GDP in 2020, with Chinese GDP predicted to overtake American GDP in the near term.

Definition 1. Dependent variable $\mathrm{W}$ and independent variable $\mathrm{G}$ denote yearly HDI attenuated GDP and yearly GDP from 1990 through 2018.

$\mathrm{W}$ and $\mathrm{G}$ are calibrated in thousands and trillions of current US dollars. These vectors are importance-weighted by a variable $\mathbf{P}$, which denotes global or national population size calibrated in billions of individuals from 1990 through 2018.

The following axiom is vulnerable to empirical verification. We test this axiom with a simple bilinear regression of W on G over 1990, ..., 2018:

Linear Axiom 1. $W=\alpha 1+\beta G$, where 1 is the unit vector and intercept $\alpha$ and slope $\beta$ are calibrated in thousands of current US\$.

Result 1. Axiom 1 is resulted by the following command which produces Table 2 in our global analysis:

$$
\text { regress } \mathrm{W} \text { G [iweight }=\mathbf{P} \text { ] }
$$

(StataCorp., 2011). The W, G, and $\mathbf{P}$ values in the $29 \times 3$ Stata dataset were accessed online from World Bank and United Nations files (cf. Sections 2 and 3).

Table 2 displays our global linear regression, with $\alpha=0.4373, \beta=0.0931$, and $\mathrm{R}^{2}=0.9989$, i.e. global $\mathrm{G}$ totally accounts for global $\mathrm{W}$. The American linear regression returns $\alpha=5.723, \beta=2.5571$, and $\mathrm{R}^{2}=0.9992$. The Chinese linear regression produces $\alpha=-0.0794, \beta=0.5402$, and $\mathrm{R}^{2}=0.9997$. The tables for the latter two national regressions are not displayed.

The American intercept and slope far exceed the intercepts and slopes for both the global and Chinese economies. The lofty American elevation is 5.723 thousand current US\$, and the steep American incline is 2.5571 thousand current US\$, i.e. a 1 trillion current US\$ rise in American GDP boosts American HDI-attenuated GDP 2.5571 thousand current US\$. In contrast, the far lower global and Chinese intercepts are 0.4373 and -0.0794 , and 1 trillion current US\$ rises in global and Chinese GDPs only result in HDI-attenuated GDP increments of 0.0931 thousand current US\$ and 0.5402 thousand current US\$.

Throughout these global and national differences in intercepts and slopes, linear axiom 1 fits perfectly at the global level and in the world's two largest economies.

Note: The total degree of freedom is 185 billion, which is the sum of 29 world 
population sizes from 1990 through 2018. This total df is partitioned into one billion $\mathrm{df}$ for this simple bilinear regression model and 184 billion $\mathrm{df}$ for its residual. The extremely close model fit is demonstrated by $\mathrm{R}^{2}=0.9989$, which shows that $\mathbf{G}$ perfectly accounts for $\mathbf{W}$ at the global level. Due to these large numbers, we ignore the last two columns of Table 2 (cf. Section 5).

\section{$\ln W$ as an Isoelastic Function of $\ln G$}

We now remodel the relation of $W$ to $G$ to be linear in $\ln W$ and $\ln G$ :

Iso-Elasticity Axiom 2. $\ln W=\alpha 1+\beta \ln G$

Result 2. Axiom 2 is resulted by the command

$$
\text { regress } \ln \mathrm{W} \ln \mathrm{G} \text { [iweight }=\mathrm{P} \text { ] }
$$

(StataCorp., 2011). This $\ln$-ln regression returns a different pattern of intercepts and slopes from our linear regression. Table 3 shows that the global $\ln -\ln$ intercept -1.9159 is far below the $\ln$-ln intercepts for the US and China. However, the global isoelastic slope 0.9076 exceeds the American isoelastic slope 0.8385. Thus, a $1 \%$ rise in global $\mathrm{G}$ produces a $0.9076 \%$ increase in global W. In contrast, a $1 \%$ rise in American $\mathrm{G}$ only produces a $0.8385 \%$ increase in American W. Interestingly, a $1 \%$ rise in Chinese G produces a $1.0612 \%$ increase in Chinese $\mathbf{W}$ (cf. Johnston, 1984: pp. 518-521).

Perfect fits of isoelastic axiom 2 are demonstrated by $\mathrm{R}^{2} \mathrm{~s}$ of $0.9991,0.9998$, and 1.0000 for the world and it's two largest economies, demonstrating that $\mathrm{W}$ elasticity is driven by $\mathrm{G}$ elasticity alone. In view of global and national contractions in $\mathrm{G}$, the results in this section strongly support international action to

Table 2. Global linear regression of $\mathrm{W}$ on $\mathrm{G}$.

\begin{tabular}{ccccc}
\hline Source & SS & df & MS & $\mathbf{R}^{2}$ \\
\hline Model & 718.8 & 1 & 718.8 & 0.9989 \\
Residual & 0.8107 & 184 & 0.0044 & \\
Total & 719.6 & 185 & 3.890 & \\
W & Coef. & Std. Err. & $\mathrm{t}$ & $P>|\mathrm{t}|$ \\
G & 0.0931 & 0.0002 & 404.7 & 0.000 \\
_cons & 0.4373 & 0.0129 & 34.02 & 0.000 \\
\hline
\end{tabular}

Table 3. Global regression of $\ln W$ on $\ln G$.

\begin{tabular}{ccccc}
\hline Source & SS & df & MS & $\mathbf{R}^{2}$ \\
\hline Model & 28.82 & 1 & 28.82 & 0.9991 \\
Residual & 0.0264 & 184 & 0.0001 & \\
Total & 28.84 & 185 & 0.1559 & \\
$\operatorname{lnW}$ & Coef. & Std. Err. & $\mathrm{t}$ & $P>|\mathrm{t}|$ \\
$\ln$ C & 0.9076 & 0.0020 & 449.4 & 0.000 \\
_cons & -1.9159 & 0.0078 & -244.5 & 0.000 \\
\hline
\end{tabular}


mitigate falling $\mathbf{W}$ (cf. Section 1).

Addendum. Following Johnston (1984: p. 61, pp. 518-521), we have the classical econometric corollary of Axiom 2:

Corollary 1. If $w$ and $g$ denote scalar values of vectors $\mathrm{W}$ and $\mathrm{G}$, then

$$
w=f(g)=\alpha g^{\beta}
$$

is the Cobb-Douglas production function, which is linearized as

$$
\ln w=\ln \alpha+\beta \ln g,
$$

with intercept ln $\alpha$ and slope $\beta$.

Definition 2. An isoelasticity function has constant elasticity over $g>0$.

Corollary 2. A function of $g$ is an isoelasticity function with constant elasticity $\beta$ if and only if the function has the form $\alpha g^{\beta}$.

\section{Data Science in a Post-Pandemic Era}

Global Data Science. Section 4 overrides "The central dogma of statistical inference, that there is a component of randomness in data" (Van Dyke et al., 2015: p. 9). "Neither denying nor quantifying uncertainty, we simply ignore it" (Bechtel, 2018: p. 8). Our axiomatic venture into sequential populations brings compelling advantages to global data science. We replace probabilistic inference by parameter computation and random variables give way to real variables $\mathrm{G}, \mathrm{W}$, and P. This suggests further "statistical thinking and new foundational frameworks" that help sort out "the many philosophical issues data science presents" (Davidian, 2013). These "philosophical issues" in data science were broached in the last century by Tukey's (1977) Exploratory Data Analysis and Mosteller and Tukey's (1977) Data Analysis and Regression: A Second course in Statistics.

In the present paper we make an axiomatic approach to data analysis. Section 4 , using definition 1 , axiom 1 , and result 1 , shows that an axiomatic venture, followed by a close model fit, can discover and corroborate "truth". Axiom 2 and result 2 then illustrate that the discovery and close fit of a particular model does not imply its uniqueness. Thus, an isoelasticity model, with a fit equally as close as it's linear counterpart, produces another "truth" via a distinct pathway.

The pandemic of 2020. In his Report to the Congress in the first quarter of 2020 the American Federal Reserve Chair Powell noted the "shocking" first quarter drop in Chinese GDP of 36\%. The drop in European GDP was 12\%, and the shrinkage in non-American GDP in the first quarter of 2020 was $13 \%$ (https://www.federalreserve.gov/newsevents/testimony/powell20190710a.htm).

Six weeks later Powell discussed the Federal Reserve's unprecedented foreign lending to mitigate global GDP contraction

(https://www.cnbc.com/world/?region=world, 13 May, 2020).

Corroborating the Federal Reserve's concerns, the IMF's Chief Economist Gita Gopinath predicted a drop in global economic outlook in 2020 (CNBC, 24 June, 2020). She also predicted that global GDP will shrink 4.9\% this year (Aljazeera, 24 June, 2020). In the second quarter of 2020 US and German GDP then 
fell $10 \%$, the largest quarterly drop for these two nations since WWII. At an annualized rate the American economy has contracted by one third of its value during the COVID-19 pandemic (CNBC and Aljazeera, 30 July, 2020).

Addressing the COVID-19 crisis, recent Oxfam data has verified that rich-nation inaction costs, stemming from poor-nation famines, low education, and civil wars, are orders of magnitude greater than proactive prevention of these tragedies (Aljazeera, 16 July, 2020). The United Nations confirms that rich countries are not contributing enough to poor countries in the COVID-19 crisis, even though this support protects rich countries too. The UN emphasizes that collaboration between its humanitarian agency, the United States, the IMF, and the World Bank is crucial for mitigating global GDP contraction that is endangering poor nations (Aljazeera, 26 September, 2020). Section 4 here provides data-driven support for this collaboration.

\section{Frontiers of GDP and Human Development}

The results in Section 4 show that linear and isoelastic transformations of GDP perfectly predict an Index of HDI-Attenuated GDP with global and national time series. These findings upgrade the debate on the nature of well-being. They also show that HDI-attenuated GDP computation can be carried out from global GDP without survey sampling, questionnaire interrogation, probabilistic inference, or significance testing. In view of trade-war and COVID-19 shocks to all economies, international attention to global GDP and human development is now compelling.

Thus far attention has been paid to sustained GDP growth by the Leeds UK Steady State Economy Conference (O’Neill et al., 2010), the United Nations Division for Sustainable Development (Costanza et al., 2012), and the Annual Forum of The Progressive Economy Initiative (Journal for a Progressive Economy, 2015). GDP growth has also been addressed by French President Sarkozy's report, which ends with the admonition that "no limited set of figures can pretend to forecast the sustainable or unsustainable character of a highly complex system" (Stiglitz et al., 2010: p. 136). Our present "political, ecological, and economic" system is "the prehistory of transformative and fundamental systemic change... Sustainability requires ... a transformative vision beyond both corporate capitalism and traditional state socialism"

(http://thenextsystem.org/principles/). This "Pluralist Commonwealth", envisioned by Gar Alperovitz (2017), escorts the political and economic activism of Mahatma Ghandi into the $21^{\text {st }}$ century.

\section{Acknowledgements}

The authors dedicate this work to the memory of their best critic, Maria Cohn Bechtel. In our introduction, Dr. Bethany Bechtel emphasized a gradual Ghandian approach to resolving societal conflicts and loosening established beliefs in a post-pandemic era. Our formulation of Section 4 has been facilitated by com- 
ments from Stewart Thomas, Aryil Bechtel, Cynthia Wang, Edward Svasta, and the reviewer. The authors thank Editor Alice Yao for her placement of this work in an international arena. This article draws upon Bechtel, G., 2018 and 2019; Bechtel, G. and Bechtel, T., 2020.

\section{Conflicts of Interest}

The authors declare no conflicts of interest.

\section{References}

Alperovitz, G. (2017). Principles of a Pluralist Commonwealth. The Next System Project. http://thenextsystem.org/principles

Autor, D. H. (2014). Skills, Education, and the Rise of Earnings Inequality among the “Other 99 Percent”. Science, 344, 843-851. https://doi.org/10.1126/science.1251868

Bechtel, G. G. (2018). The Human Development Index as Isoelastic GDP: Evidence from China and Pakistan. Economies, 6, 32. https://doi.org/10.3390/economies6020032

Bechtel, G. G. (2019). GDP Is Well-Being. Open Journal of Social Sciences, 7, 189-204. https://doi.org/10.4236/jss.2019.712014

Bechtel, G. G., \& Bechtel, T. G. (2020). American GDP Alone Predicts Human Development. Advances in Social Sciences Research Journal, 7, 273-282. https://doi.org/10.14738/assrj.79.9012

Costanza, R., Alperovitz, G., Daly, H., Farley, J., Franco, C., Jackson, T., Kubiszewski, I., Schor, J., \& Victor, P. (2012). Building a Sustainable and Desirable Economy-in-Society-in-Nature. New York: United Nations Division for Sustainable Development. https://doi.org/10.22459/BSDESN.12.2013

Davidian, M. (2013). Aren't We Data Science? Amstat News, July, 3-5.

Johnston, J. (1984). Econometric Methods (3rd ed.). New York: McGraw-Hill.

Journal for a Progressive Economy (2015). Sustainable Growth: The Challenge of Transition. Annual Forum, June 2015. Brussels: The Progressive Economy Initiative.

Keynes, J. M. (1940). The General Theory of Employment, Interest and Money. Harcourt, Brace \& World.

Masood, E. (2016). The Great Invention: The Story of GDP and the Making and Unmaking of the Modern World. New York: Pegasus Books Ltd.

Mosteller, F., \& Tukey, J. W. (1977). Data Analysis and Regression: A Second Course in Statistics. Reading, MA: Addison-Wesley Pub Co.

O'Neill, D., Dietz, R., \& Jones, N. (2010). Enough Is Enough: Ideas for a Sustainable Economy in a World of Finite Resources. The Report of the Steady State Economy Conference, Leeds: Center for the Advancement of the Steady State Economy and Economic Justice for All.

Reardon, S. F. (2012). The Widening Academic Achievement Gap between the Rich and the Poor: New Evidence and Possible Explanations. In G. J. Duncan, \& R. J. Murnane (Eds.), Wither Opportunity? Rising Inequality, Schools, and Children's Life Chances (pp. 91-116). New York: Russell Sage Foundation.

Singh, A., Nabar, M., \& N'Diaye, P. (2013). China's Economy in Transition: From External to Internal Rebalancing. Washington DC: International Monetary Fund.

StataCorp. (2011). Stata Statistical Software, Release 12. College Station, TX: StataCorp LP. 
Stiglitz, J. E., Sen, A., \& Fitoussi, J.-P. (2010). Mismeasuring Our Lives: Why GDP Doesn't Add Up: The Report of the Commission on the Measurement of Economic Performance and Social Progress. New York: The New Press.

Taylor, C. E., \& Hall, M.-F. (1967). Health, Population, and Economic Development. Science, 157, 651-657. https://doi.org/10.1126/science.157.3789.651

Tukey, J. W. (1977). Exploratory Data Analysis. Reading, MA: Addison-Wesley Pub Co.

Van Dyke, D., Fuentes, M., Jordan, M., Newton, M., Ray, B., Lang, D., \& Wickham, H. (2015). American Statistical Association Statement on the Role of Statistics in Data Science. Amstat News, October, 9.

Van Raalte, A. A., Sasson, I., \& Martikainen, P. (2018). The Case for Monitoring Life-Span Inequality. Science, 362, 1002-1004. https://doi.org/10.1126/science.aau5811 